\title{
A questão agrária na prática pedagógica dos/as professores/as egressos/as da LEC/UFBA: o desafio de efetivar o projeto de escolarização da classe trabalhadora
}

Janeide Bispo dos Santos ${ }^{1}$

${ }^{1}$ Universidade do Estado da Bahia - UNEB. Departamento de Educação, Campus XI. Rua Álvaro Augusto, s/n, Rodoviária. Serrinha - BA. Brasil.

Autor para correspondência/Author for correspondence: janeidebsantos@gmail.com

RESUMO. Este artigo apresenta resultados de uma pesquisa que analisou o trabalho pedagógico realizado por professores(as) egressos(as) do curso de Licenciatura em Educação do Campo (LEC) da Universidade Federal da Bahia (UFBA). Problematiza-se as contradições da sociedade capitalista para explicitar os rebatimentos sobre a classe trabalhadora em termos de exclusão e limitações no acesso aos bens materiais e culturais. Levanta-se a questão agrária como uma questão fundante da sociedade capitalista e seus desdobramentos sobre a classe trabalhadora. Apresenta-se a Educação do Campo como projeto da classe trabalhadora cujo intuito é enfrentar a ordem estrutural posta pela sociedade burguesa. Analisa-se o trabalho pedagógico dos sujeitos da pesquisa à luz dos quatro pilares que alicerçaram o Projeto Político do Curso (PPC), a saber: consistente base teórica, formação política, consciência de classe e organização revolucionária com inserção nas lutas de classes com olhar direcionado para o trato pedagógico dado à categoria questão agrária, tendo em vista confrontar a concepção da formação e a prática dos(as) docentes no que diz respeito à implementação de uma prática pedagógica revolucionária. Os dados da pesquisa revelam que nem todos(as) os(as) docentes incorporaram a concepção de conteúdo e do método da formação às suas respectivas práticas.

Palavras-chave: educação do campo, questão agrária, prática pedagógica. 


\title{
The agrarian issue in the pedagogical practice of LEC/UFBA educational teachers: the challenge of implementing the working class schooling project
}

\begin{abstract}
This article presents the results of a research that analyzed the pedagogical work carried out by teachers graduated from the Course in Rural Education (LEC) at the Federal University of Bahia (UFBA). The contradictions of capitalist society are problematized to explain the repercussions on the working class in terms of exclusion and limitations in the access to material and cultural goods. The agrarian question is raised as a fundamental question of the capitalist society and its unfoldings on the working class. Rural Education is presented as a project of the working class whose aim is to face the structural order posed by bourgeois society. The pedagogical work of the research subjects is analyzed in the light of the four pillars that founded the Political Project of the Course (PPC), namely: consistent theoretical basis, political formation, class awareness, and revolutionary organization with insertion in class struggles with a look towards the pedagogical treatment given to the agrarian issue category, bearing in mind to confront the conception of the training and the teachers' practice in regards to the implementation of a revolutionary pedagogical practice. The research data reveals that not all teachers incorporated the conception of the content and method of the training to their respective practices.
\end{abstract}

Keywords: rural education, agrarian question, pedagogical practice 


\section{La cuestión agraria en la práctica pedagógica de los/las profesores/as egresos/as de la LEC/UFBA: el reto de efectivar el proyecto de escolarización de la clase trabajadora}

RESUMEN. Este artículo presenta los resultados de una investigación que analizó el trabajo pedagógico realizado por profesores(as) egresados(as) del curso de Licenciatura en Educación Rural (LEC) de la Universidad Federal de Bahía (UFBA). Fueron problematizadas las contradicciones de la sociedad capitalista para explicar los rebatimientos sobre la clase trabajadora en términos de exclusión y limitaciones en el acceso a los bienes materiales y culturales. La cuestión agraria se levanta como una cuestión precursora de la sociedad capitalista y sus desdoblamientos sobre la clase trabajadora. La Educación Rural se presenta como un proyecto de la clase trabajadora cuyo objetivo es enfrentar el orden estructural puesto por la sociedad burguesa. El trabajo pedagógico de los sujetos de investigación se analiza a la luz de los cuatro pilares que sustentaron el Proyecto Político del Curso (PPC), a saber: base teórica consistente, formación política, conciencia de clase y organización revolucionaria con inserción en las luchas de clases con una mirada dirigida al tratamiento pedagógico dado a la categoría cuestión agraria, objetivando confrontar la concepción de la formación y de la práctica de los(las) docentes en cuanto a la implementación de una práctica pedagógica revolucionaria. Los datos de la investigación revelan que no todos los(las) docentes incorporaron la concepción de contenido y del método de formación en sus respectivas prácticas.

Palabras clave: educación rural, cuestión agraria, práctica pedagógica. 


\section{Introdução}

Neste artigo, apresenta-se resultados de uma pesquisa que teve como objeto de estudo o trabalho pedagógico dos egressos do curso de Licenciatura em Educação do Campo (LEC) da Universidade Federal da Bahia (UFBA). O curso de Licenciatura em Educação do Campo foi um dos quatro projetos pilotos oriundos do edital do primeiro edital do Programa de Apoio à Formação Superior em Licenciatura em Educação do Campo (PROCAMPO) do Ministério da Educação (MEC), por intermédio da, na época, Secretaria de Educação Continuada, Alfabetização e Diversidade (SECAD), lançado no ano de 2007. Nesse edital, o MEC convidava universidades públicas a apresentarem propostas de licenciaturas que se comprometessem com a formação de professores e professoras para a Educação do Campo.

Das propostas apresentadas, quatro foram aceitas pelo MEC e os cursos autorizados, a saber: Universidade Federal da Bahia (UFBA), Universidade Federal de Sergipe (UFS), Universidade de Brasília (UnB) e Universidade Federal de Minas Gerais (UFMG). O curso da UFBA foi realizado no período de 2008-2013. De acordo com PPC/LEC/UFBA (2008), o curso teve propósito de formar professores(as) para escolas do campo com base nas demandas levantadas pelos(as) camponeses(as) organizados em movimentos de lutas populares, e demarca a Educação do Campo como uma possibilidade tática para enfrentamento aos impactos que os processos sociais capitalistas têm provocado sobre a classe trabalhadora camponesa.

Com base na delimitação supramencionada, esta pesquisa acompanhou o trabalho pedagógico de seis dos(as) professores(as) egressos(as) da LEC ao longo de aproximadamente um ano e meio. No Projeto Político do Curso (PPC LEC/UFBA), foi demarcado que a consolidação da escolarização da classe trabalhadora depende de quatro fundamentos básicos: consistente base teórica, formação política, consciência de classe e organização revolucionária com inserção nas lutas de classes.

Nesta pesquisa, analisou-se o trabalho educativo realizado pelos professores egressos da LEC/UFBA com o intuito de identificar em que nível os instrumentos culturais apresentados no PPC do curso, identificados como instrumentos teóricos fundamentais para consolidar o projeto de escolarização da classe trabalhadora, se consolidaram no âmbito da ação dos docentes. De acordo com o PPC/LEC/UFBA (2008), a 
formação teve a meta de colocar o conhecimento científico a serviço da classe trabalhadora, neste caso, especialmente da classe camponesa para fortalecê-la no contexto da luta de classes.

O conhecimento trabalhado durante o curso tinha como objetivo tático a consolidação de um professor que dominasse o conteúdo da sua área de conhecimento, mas que também se apropriasse da base teórica do materialismo histórico-dialético, construísse uma formação política, desenvolvesse a consciência de classe e se inserisse nos movimentos de lutas populares na defesa de outro projeto societário e na luta pela reforma agrária.

Neste artigo, abre-se uma seção para apresentar a problemática da questão agrária no contexto da sociedade burguesa considerando a importância da concentração da terra para a essa classe e a problemática que rebate sobre a classe trabalhadora. Nesse sentido, a questão agrária é entendida como uma problemática que extrapola a questão fundiária e se desdobra em inúmeras questões sociais no campo ou na cidade. Na mesma seção também se apresenta a metodologia da pesquisa e, na seção seguinte, apresenta-se os resultados da pesquisa e, em seguida, tecem-se as considerações finais.
Os desdobramentos da questão agrária sobre a classe trabalhadora e a LEC como possibilidade de enfrentamento

Entende-se por questão agrária as questões sociais oriundas dos desdobramentos provenientes da estrutura fundiária sobre a população. A formatação da estrutura fundiária foi estabelecida a partir da apropriação privada da terra e da natureza pelo capital, fato que impacta nas condições socioespaciais da classe trabalhadora (Germani, 2006).

O Brasil é um dos países com maior concentração fundiária do mundo. Houve um aumento considerável entre os dados do Censo Agropecuário de 2006 em relação ao de 2017. Em 2006, o Brasil tinha $45 \%$ das terras dentro dos estabelecimentos com mais de mil hectares, em 2017 são 47,5\% das terras. Contudo, a terra está mais concentrada ainda, pois 2006 eram 5.175.636 estabelecimentos, já em 2017 registra-se 5.072.152. Mais de 16 milhões de hectares estão concentrados nos grandes estabelecimentos, enquanto os menores, que têm até dez hectares, representam $50,2 \%$ do número total de estabelecimentos, mas ocupam apenas 2,3\% da área do país. Contudo, é relevante considerar que a estrutura fundiária se refere a uma das dimensões para se analisar a questão agrária, mas ela não é a 
questão agrária em si. A questão agrária está situada na lógica do modo de produção capitalista.

A terra é natureza natural, pode-se dizer que ela não é resultado do trabalho, pois antecede o homem - sua essência original, portanto, não é o capital. Mas, a partir do momento em que ela se tornou propriedade privada, seu dono tornou-se proprietário legítimo da riqueza que dela é proveniente. A propriedade da terra funda o princípio da propriedade privada, pois “a dominação da propriedade privada começa com a posse fundiária, ela é a sua base" (Marx, 2004, p. 74) e, no capitalismo, tornar-se-á propriedade.

Marx (1988), ao analisar os estudos de Adam Smith e David Ricardo, conclui que a renda absoluta vem da propriedade privada que dá "direito" ao proprietário auferir a renda da terra. A renda absoluta considera os processos socioespaciais como um todo, pois está ligada à existência da propriedade privada do solo monopolizada por um grupo social específico. Ele não nega a existência das demais rendas da terra, as chamadas rendas diferenciais, mas compreende que elas se limitam à esfera da agricultura, enquanto a renda absoluta provém do próprio movimento do modo de produção capitalista.
A renda da terra é um tributo pago por todas as pessoas que estão inseridas na ordem mercantil para os sujeitos que têm o monopólio da terra, estejam elas produzindo ou não. A terra é natureza, é o substrato da vida, é dela que se retira direta ou indiretamente todas as mercadorias e nela que se constroem as moradias. Mas essa terra está concentrada nas mãos de poucos, e esses poucos cobram pelo uso. Quais são as formas de cobrança? Existe a cobrança pelo arrendamento ou pela localização, mas a principal delas é realizada de forma indireta, quando os latifundiários monopolistas indisponibilizam ou controlam a quantidade de terra, o destino do produto e a localização da terra que será disponibilizada para a produção. Isso eleva o preço de todas as mercadorias, inclusive da mercadoria terra. Esse processo condenou a classe trabalhadora a se tornar detentora exclusivamente da força de trabalho, desprovida da terra e do capital.

A classe trabalhadora paga pela concentração da propriedade da terra nas mãos do capital a partir das suas próprias condições de existência, pois tudo que eles necessitam de básico para viver precisa ser comprado, inclusive o pedaço de solo para construir as casas ou enterrar os restos mortais. Os que não conseguem vender a força de trabalho ou obter salários que 
sejam suficientes para pagar pelo que necessitam são condenados a viver nas mais diversas condições de miséria e desumanização. Desse modo, a renda da terra é um preço pago a um grupo por ter o monopólio da terra que, em muitos casos, fica sem produzir. Sendo assim, a questão agrária é algo real, vivido por todos, não é algo inventado, é a base para explicação da concentração da riqueza nas mãos dos donos dos meios de produção, em detrimento da pauperização da população que constitui a classe trabalhadora. Por essa razão, "a questão agrária engole a todos e a tudo, quem sabe e quem não sabe, quem vê e quem não vê, quem quer e quem não quer” (Martins, 1994, p. 12-13). A questão agrária é muito mais ampla do que muitos imaginam: ela traz implicações sociais para a humanidade do ponto de vista contraditório do próprio processo de humanização.

A ideia de Marx de que o homem, ao modificar a natureza, modifica-se a si próprio, contém os fundamentos para a compreensão do trabalho enquanto produto de atividades dirigidas e que impulsionam o intercâmbio dos homens com a natureza, pretextando criar valores de uso às necessidades humanas. Vale lembrar que, no tocante à satisfação das necessidades humanas, a apropriação da natureza é crucial para a vida em qualquer sociedade, sendo antes comum a todas as formas sociais. (Thomaz Júnior, 2009, p. 111).

A transformação da terra em mercadoria fez modificar o homem, pois a exclusão da terra privou um grupo social do acesso às condições de satisfação das necessidades humanas, haja vista que a terra é substrato da vida. Por outro lado, o grupo que é proprietário dos meios de produção passou a esbanjar muita riqueza. Essa relação socioespacial que alicerça a sociedade de classes se configura no arranjo espacial materializando-se nos efeitos das suas diferenças e, ao mesmo tempo, expressa a correlação de forças, as conflitualidades e os conflitos territoriais, pois ela constrói simultaneamente e em posições opostas, onde um é a negação do outro. É nesse contexto que a questão agrária é demarcada.

Para Martins (1981), a questão agrária produz simultaneamente a concentração da riqueza e a expansão da pobreza e da miséria. Essa desigualdade é resultado de um conjunto de fatores políticos, econômicos e socioespaciais. A questão agrária não tem limites e fronteiras: ela se faz presente no campo e na cidade, pois trata-se de uma questão estrutural. O campo e a cidade também não se excluem, uma vez que as cidades contemporâneas foram constituídas por uma massa de trabalhadores que, 
desprovida da propriedade da terra, foi "expulsa" do campo e se tornou mão de obra do capital nas cidades. Eles continuam brigando por terra, agora na forma de moradia/teto ou pela reforma agrária como estratégia para voltar para a terra e para o território. Contudo, a renda da terra só poderá deixar de existir em outro projeto de sociedade, pois, no capitalismo, ela continuará sendo a mola mestra para a especulação e para o fortalecimento do desenvolvimento desigual e combinado, conforme Smith (1988).

Para Smith (1988), o desenvolvimento desigual é tanto o produto quanto a premissa geográfica do desenvolvimento capitalista. Ele entende que, como produto, trata-se de algo altamente visível na paisagem do capitalismo, tal como a diferença entre espaços desenvolvidos e subdesenvolvidos em diferentes escalas. Já como "premissa da expansão capitalista, o desenvolvimento desigual é a desigualdade social estampada na paisagem geográfica e é simultaneamente a exploração daquela desigualdade geográfica para certos fins sociais determinados" (Smith, 1988, p. 221). É nessa conjuntura em que vive a maior parte da população camponesa: a exclusão da terra e do território também a exclui do acesso a outros bens materiais e imateriais, dentre eles o conhecimento sistematizado, que é peculiaridade da educação escolar.

Qual é a realidade da escola burguesa que é proposta para a classe trabalhadora? Tratar da educação que é oferecida à classe trabalhadora brasileira requer uma consideração sobre a estruturação da educação no Brasil. Segundo Frigotto (2010), à medida que o sistema capitalista foi se solidificando, os sistemas educacionais também se estruturaram. Contudo, estes últimos se compuseram a partir da defesa de uma universalização do ensino dualista que, no Brasil, foi estabelecido entre escola pública e escola privada. Elas se constituem, respectivamente, assim: a escola de poucos conteúdos para os filhos dos trabalhadores e a escola formativa, clássica, para os filhos da burguesia ou filhos dos trabalhadores mais qualificados que se esforçam para pagar mensalidades que são superiores à renda familiar média da maioria da população brasileira. Levando em consideração essa divisão, questionase: por que a escola pública, a escola voltada para a classe trabalhadora, tem sido consolidada como espaço de consolidação da hegemonia nos seus conteúdos e metodologias. Tal fato retira a possibilidade de formação numa 
perspectiva emancipatória e ligada a classe social a que se destina.

O fio da história da educação no Brasil aponta que a institucionalização do sistema nacional de ensino foi efetivada em 1930. Contudo, ela não foi pensada para atender à classe trabalhadora: a linha que tem guiado a política educacional brasileira tem sido firmada pela concepção de educação que visa atender às demandas postas pelo mercado. A posição políticoeconômica ocupada pelo Brasil, enquanto periferia do capital internacional, fez com que o país concebesse sua política educacional como objeto de ajuste, tendo em vista atender às demandas postas pelo capital internacional. Tal situação foi confirmada com o seu alinhamento às propostas estabelecidas pelo capital internacional dos países centrais no “Consenso de Washington". Desse modo, a política educacional brasileira tornou-se território controlado pelo capital e, nessas circunstâncias, cabe à classe dominada um projeto de educação que é pensado por quem a domina.

A escola concebida para a classe trabalhadora não dá conta de "propiciar a aquisição dos instrumentos que possibilitam o acesso ao saber elaborado (ciência), bem como o próprio acesso aos rudimentos deste saber" (Saviani, 2005, p. 15). Os rudimentos mencionados pelo autor dizem respeito ao saber ler e escrever, a ler o espaço e a conhecer a linguagem dos números, da natureza e da sociedade. Segundo Lefebvre (1991), a conjuntura das forças produtivas não acarreta somente a produção de objetos, mas também a reprodução das relações sociais, pois o ciclo de produçãocirculação-troca-consumo tem um caráter social que se materializa no espaço. Na análise social defendida por Lefebvre, identificam-se os grupos que são produtores de espaço e os grupos que são reprodutores.

Os indivíduos da classe trabalhadora vão para a escola aprender a se reproduzir enquanto classe trabalhadora sem, contudo, construir a consciência de classe, haja vista que o ensino escolar não está voltado para a garantia do acesso ao conhecimento, muito menos para a elevação do pensamento teórico dos estudantes. Nesse sentido, compreende-se que o Estado, na sociedade capitalista, tem assumido o papel de agente que media os interesses do capital, o que confirma a tese de Engels, pois "o Estado da classe dominante é, de qualquer modo, essencialmente máquina destinada a reprimir a classe oprimida e explorada" (Engels, 2012, p. 166). Desse modo, considera-se que o acesso ao conhecimento é um meio em que o homem se humaniza, mas, por conta das 
circunstâncias materiais em que a espécie humana vive e interage socialmente, há humanos que não têm acesso às condições necessárias para o desenvolvimento dessa sociabilidade tão necessária ao processo de humanização.

Muitos dos indivíduos que reproduzem o espaço constroem uma falsa consciência sobre a realidade. Marx e Engels (2009) chamam de falsa consciência aquela que não representa a própria existência do indivíduo, mas uma compreensão a partir dos interesses da burguesia. Isso permite a criação de um conhecimento parcial, abstrato, que esconde a essência e permite que se veja apenas a aparência das coisas, um pseudoconhecimento. Em virtude disso, muitos indivíduos são ofuscados de conhecer os fundamentos da realidade, fato que fragiliza as possibilidades de organização na luta pela transformação da ordem social posta. É nessas circunstâncias que a Educação do Campo, como uma “experiência de classe" (Caldart, 2010), envolve diferentes sujeitos e, ao entrar no território das políticas públicas, estabelece relação com o Estado, mas, ao se colocar na luta em defesa da classe trabalhadora do campo, pressiona o mesmo Estado para garantir uma educação que permita o acesso a um conhecimento problematizador da sociedade e do projeto de ensino burguês, do mesmo modo que defende a reforma agrária em detrimento do latifúndio e de todas as diferenças sociais postas pela sociedade de classes.

A Educação do Campo é um território, é um campo de força: ela é um movimento real de combate ao atual estado de coisas: movimento prático, de objetivos ou fins práticos, de ferramentas práticas, que expressa e produz concepções teóricas, críticas a determinadas visões de educação, de política de educação, de projetos de campo e de país, mas que são interpretações da realidade construídas em vista de orientar ações/lutas concretas. (Caldart, 2010, p. 20, grifo do autor). A Educação do Campo não se expressa na prática socioespacial com o nome de Educação do Campo, mas nas ações em defesa de uma dada concepção de homem, de sociedade e de espaço geográfico. Tais concepções têm como base um projeto histórico de superação ao projeto do capital. No PPC/LEC/UFBA (2008), explicita o que entende por Educação do Campo:

Por educação do campo entendemos o processo de formação dos trabalhadores, através de uma política cultural, em um contexto de antagonismos de classe onde estão em disputa projetos históricos e de escolarização. São concepções que asseguram aos povos do campo uma educação ao seu modo de viver, pensar e produzir que pode indicar a emancipação humana ou a alienação 
humana. Ao defendermos, portanto, a educação do campo, referenciada em um projeto histórico superador, estamos nos referindo à formação dos trabalhadores que hoje reivindicam uma educação do campo na perspectiva da emancipação humana. (PPC/LEC/UFBA, 2008, p. 2-3).

Assim, a expressão "Educação do Campo" é carregada de sentido filosófico, ético, político, sociológico, antropológico, histórico e geográfico. Não se trata de uma expressão genérica, mas de um movimento de combate aos processos socioespaciais que são orientados por um projeto de sociedade que condena um grupo de pessoas a viver destituído do acesso às produções humanas e a elementos básicos necessários à sobrevivência, como água, terra, moradia e alimentos, dentre outros. Nessa conjuntura, a terminologia "Educação do Campo" parte da reação dos movimentos sociais que são comprometidos com o enfrentamento da questão agrária, na defesa de outro projeto de sociedade.

As propostas de ações que vão em direção a uma concepção de homem, de sociedade e de espaço geográfico distinta da ordem burguesa são conduzidas por várias frentes que se inter-relacionam; dentre elas está a frente que propõe o projeto de educação para a classe trabalhadora no enfrentamento à escola burguesa. Ela tem como meta a superação de determinadas visões "ingênuas" de educação, de política de educação, de ensino escolar, de formação de professores e de projetos de campo e de país. Desse modo, justifica-se que "a Educação do Campo não é uma proposta de educação. Mas enquanto crítica da educação em uma realidade historicamente determinada ela afirma e luta por uma concepção de educação (e de campo)" (Caldart, 2010, p. 20).

A tática empregada pela proposta do curso de LEC/UFBA, demarcada em seu PPC, objetivava a formação de professores militantes culturais, cuja formação os permitisse atuar politicamente na defesa do projeto histórico referenciado pelos movimentos sociais que representam a classe trabalhadora. Para tanto, defendeuse também uma educação pública de qualidade e referenciada nas lutas sociais. Assim, levou em consideração que:

O foco da educação é o ensino aprendizagem do conhecimento científico, com base no trabalho humano, que vem possibilitando ao educando, como sujeito histórico, o instrumental teórico necessário para o posicionamento crítico ante as problemáticas específicas do campo, a ciência moderna e a questão socioambiental do mundo atual, e as questões que tencionam a luta de classes no campo. (Taffarel et al., 2011, p. 69).

A educação e a escola, historicamente, foram usadas como espaços de naturalização das questões 
sociais que são demarcadas pelas diferenças socioespaciais estabelecidas no contexto do modo de produção em vigor. Por isso, o PPC/LEC/UFBA teve como meta consolidar uma formação docente fundamentada numa consistente base teórica, tendo em vista compreender a dinâmica dos processos sociais, tendo um olhar particular para a classe camponesa. Além do mais, defendeu a ideia de qual sujeito se quer formar e a perspectiva da atuação depois de formado, objetivando a defesa de um dado projeto histórico.

O controle da produção intelectual pela classe dominante, assim como qualquer processo social, não é absoluto, o que dá condição para o conhecimento crítico também coexistir, mesmo sendo visto como subversivo para a ordem dominante: é subversivo porque permite a leitura e a compreensão da realidade nas múltiplas dimensões. É nesse processo que se situam os conflitos e as conflitualidades da ordem socioespacial que se instala um campo de forças movimentado por interesses distintos. Emerge um território, regido por uma “ordem" legal. Essa "ordem", que é estabelecida pelas leis e normas que regulam a sociedade, não tem origem abstrata: ela emana dos embates estabelecidos na base socioespacial concreta, na luta de classes. Tais leis e normas são, na sua essência, as estratégias estabelecidas pela classe burguesa para conter qualquer ameaça à sua condição de dominante, ou seja, qualquer ameaça ao que ela tem como propriedade privada, especialmente a propriedade privada da terra.

De acordo com Moreira (2012), os levantes sociais são resultantes das tensões estruturais provocadas pela ordem burguesa - são os contraespaços (ou seja, lutas por espaço). Não se trata daquele espaço que segrega e exclui, mas de um contraespaço, isto é, espaço livre do domínio, espaço da luta contra o espaço instituinte da ordem dominante. Luta-se por outra dinâmica socioespacial, por outro projeto societário, luta-se por outro espaço. Assim, os territórios são estabelecidos pela dinâmica das classes em movimento, num verdadeiro campo de forças.

A classe subalterna se organiza com o objetivo de criar táticas que deem condições de enfrentar a hegemonia posta pela classe dominante. A possibilidade vem das condições reais que podem transformar uma realidade em outra qualitativamente superior. Mas, para a possibilidade se tornar realidade, é preciso que se crie as condições necessárias para a sua realização, é preciso que a classe trabalhadora tenha acesso ao conteúdo político da luta de classes, ou seja, à realidade. 
À medida que se elevam as tensões entre as classes sociais, a disputa por/no espaço se intensifica. Surgem diferenças que carecem de ser resolvidas no plano da prática, na medida em que essa prática esteja fundamentada em uma teoria revolucionária. Ao levar-se em consideração o fato de que o acesso aos conhecimentos qualifica o processo de trabalho, ou seja, a atividade humana, a prática social, pergunta-se: em que medida o trabalho pedagógico dos professores e professoras egressos e egressas do curso LEC/UFBA estão contribuindo para a efetivação de um projeto de escolarização que visa enfrentar a questão agrária e, simultaneamente, o arranjo do espaço geográfico tecido pelo modo de produção capitalista?

\section{Metodologia}

Para responder à questão de pesquisa apresentam-se os procedimentos que foram seguidos.

A investigação foi sustentada por um conjunto de pesquisas concomitantes. Além da pesquisa bibliográfica, que deu sustentação teórico-conceitual, fez-se um estudo de documentos que tratavam do posicionamento do camponês no movimento da prática social, na defesa da reforma agrária e na consolidação do projeto de Educação do Campo. Assim, demarcou-se a concepção de Educação do Campo que é defendida pelos movimentos sociais camponeses de lutas populares. Nessas demarcações, pontuou-se a concepção de homem, de sociedade, de educação e de campo que está sendo defendida pelos movimentos de lutas populares e disputadas no âmbito da prática socioespacial.

O estudo deu subsídio para se analisar o PPC/LEC/UFBA tendo em vista a identificação dos pontos de consonância do projeto de formação docente para a LEC com o projeto de Educação do Campo da classe trabalhadora organizada em movimentos sociais populares de luta na/pela terra. O PPC/LEC/UFBA (2008) aponta que a consolidação da escolarização da classe trabalhadora depende de quatro fundamentos básicos: consistente base teórica, formação política, consciência de classe e organização revolucionária com inserção nas lutas de classes. Ao fazer a defesa da formação numa consiste base teórica, define o materialismo históricodialético como teoria e método que permite entender o real e organizar a sociedade no enfrentamento às contradições postas pelos desdobramentos da questão agrária sobre a classe trabalhadora camponesa. Além disso, destaca que o não acesso à escola por parte de muitos trabalhadores, do campo e da cidade, bem como o 
rebaixamento da formação dos que tiveram acesso, precisa ser combatida na formação em Educação do Campo que se consolide enquanto projeto de classe. Tal projeto de classe se concretiza em teoria e método. Os seja, há demarcação de uma teoria pedagógica e de uma teoria educacional que está em defesa.

De acordo com Freitas (1987), a teoria educacional se fundamenta numa teoria do conhecimento: ela contém uma concepção de educação apoiada por um projeto histórico que visa romper com a ordem hegemônica, ou mantê-la, se fundamentada nas relações entre educação e sociedade, a partir de uma perspectiva ontológica de homem que se quer formar. Apesar de não estar explícito, a partir das explicações de Freitas, compreende-se que o materialismo histórico-dialético também é a teoria educacional. Já no que diz respeito à teoria pedagógica, a formação dos/as professores(as) foi guiada pela pedagogia histórico-crítica e pela psicologia histórico-cultural. Já a temática da questão agrária foi tratada como tema integrador de todos os eixos formativos.

Após a análise do PPC, partiu-se para analisar os documentos que compõem a memória da LEC/UFBA arquivados nas dependências do Grupo de Estudos e Pesquisa em Educação Física, Esporte e Lazer (LEPEL). Esses documentos que compõem o banco de dados do curso foram analisados com o intuito de levantar subsídios sobre: quem são os egressos, onde moram, onde trabalham e, mais especificamente, em que condições de aprendizagem eles ingressaram na LEC (no que se refere ao acúmulo de conhecimento), qual a concepção de projeto histórico defendida e quais os posicionamentos nas lutas populares em defesa da reforma agrária no contexto do ingresso no curso.

A Pesquisa Didática do curso também foi consultada: os relatórios das atividades de retorno realizadas no tempocomunidade, os projetos de intervenção das áreas de conhecimentos, as atas dos encontros de formação nas áreas de conhecimento, as mídias audiovisuais com gravações dos seminários, das palestras e das oficinas de formação, vídeos das aulas ministradas e das defesas de Trabalho de Conclusão de Curso (TCC). A análise desses documentos permitiu fazer constatações não apenas da prática social inicial dos egressos na condição de professores-alunos da LEC, mas também das condições em que o curso foi implementado na conjuntura da política pública, na estrutura da UFBA e na realidade do quadro docente e discente.

De posse dos dados supramencionados, recorreu-se ao banco 
de dados do Grupo de Pesquisa "A Geografia dos Assentamentos na Área Rural” (GEOGRAFAR, 2017), com o intuito de analisar a estrutura fundiária dos municípios de morada e atuação profissional dos, então, professores-alunos da LEC/UFBA, bem como as formas de acesso à terra presentes naqueles municípios. Para identificar os professores egressos da LEC/UFBA que contribuíram com a pesquisa e, ao mesmo tempo, manter o anonimato, eles foram classificados por sexo e organizados em dois grupos: o grupo dos professores e o grupo das professoras. Os nomes, após serem dispostos em ordem alfabética, foram substituídos por números: dos 46 egressos, são 39 do sexo feminino e 7 do sexo masculino.

Posteriormente à análise da prática social inicial por meio da pesquisa documental, fez-se contato com dez dos professores(as) egressos(as). Tendo em vista a extensão territorial do estado da Bahia e o fato desta pesquisa não ter tido financiamento, o critério de escolha da amostra para a sua realização foi a localização do município onde os/as egressos/as residiam. Os seis participantes da pesquisa de campo moram em municípios do Recôncavo Baiano e Vale do Jiquiriçá, Territórios não muito distantes da capital e de fácil acesso. São cinco professoras e um professor. A pesquisa foi realizada no ano de 2015.

\section{A prática pedagógica dos(as) professores(as) alunos(as) da LEC/UFBA: ruptura ou permanência?}

O resultado da análise documental diz que a maioria absoluta dos/as egressos(as), ao entrarem no curso, não tinha nenhuma relação com os movimentos de lutas populares, tampouco sabiam o que era questão agrária. O edital do curso foi voltado exclusivamente para docentes da educação básica em escolas rurais: assim, de acordo com os dados sistematizados na pesquisa didática do curso, apenas 12\% dos (as) ingressantes tinham envolvimento com organizações campesinas, participando de atividades dos sindicatos rurais e nas associações de moradores das comunidades onde residiam. A mesma pesquisa que levantou a prática social inicial dos/as professores/alunos/as da LEC/UFBA foi aplicada novamente no término do curso. No término, o percentual de professores/as que tinham participação em lutas sociais camponesas era de $80 \%$.

A inversão nos dados é resultado da formação docente na LEC. Para ter acesso aos subsídios que viessem revelar o trato que os/as docentes egressos(as) dão à categoria à questão agrária e seus desdobramentos socioespaciais no trabalho pedagógico, seguiu-se os seguintes 
procedimentos: observação direta do trabalho docente; análise dos planos de trabalho, dos relatórios de atividades desenvolvidas pelos docentes; de entrevistas individuais; e, de respostas a um questionário constituído por 25 questões abertas. Para fins deste artigo, apresenta-se os resultados da pesquisa no que diz respeito ao trato à categoria de análise questão agrária/agrícola no trabalho pedagógico nas escolas do campo. Os critérios estabelecidos para a análise do trabalho trazem implicitamente a perspectiva de teoria educacional e de projeto de classe.

A relação existente entre o trabalho docente e os elementos que constituem os critérios de avaliação da categoria de análise foi sistematizada com base em três indicadores que classificam a dimensão qualitativa da categoria presente no trabalho pedagógico. Assim, quando o trabalho docente dos professores investigados foi submetido aos critérios propostos para avaliação e não apresentaram relação com o que está sendo avaliado, compreendeu-se que o professor não domina a categoria. Quando ele apresentou indicativos de que os critérios foram preenchidos de forma parcial, compreendeu-se que há um domínio de forma parcial. E quando o trabalho docente apresentou domínio de todos os critérios, compreendeu-se que o professor tem total domínio da categoria no contexto do trabalho pedagógico.

\section{O trato dado à questão agrária no trabalho pedagógico dos docentes egressos(as) da LEC/UFBA}

A questão agrária é oriunda de um processo social: tal processo, que também é produto social, tece concomitantemente o arranjo da sociedade e o arranjo do espaço. Buscou-se entender em que medida o trabalho dos(as) professores(as) egressos da LEC/UFBA se compromete com a luta na defesa da reforma agrária, a partir do tensionamento aos problemas agrários e agrícolas oriundos da forma como o capital explora o campo brasileiro. Como se sabe, foi desse conflito que a própria Licenciatura em Educação do Campo se originou.

Com base nos critérios que foram estabelecidos, analisou-se o trabalho docente dos seis professores. Para analisar esta categoria, tomou-se como referência o trabalho de mestrado de Ramos (2013). Essa pesquisadora, ao analisar os TCCs de 41 professores egressos da LEC/UFBA, dentre outras categorias, analisou a categoria Reforma Agrária. Na análise, levou em consideração se, quando esta era mencionada nos TCCs, os autores dos trabalhos a relacionavam com a luta pela reforma agrária, com a luta por uma 
Educação do Campo, bem como se eles a identificavam no processo de disputa de projetos antagônicos para o campo. Ramos constatou que apenas $24 \%$ dos trabalhos contemplaram esse movimento.

Aqui analisou-se, dentre outras categorias, a Questão Agrária e seus desdobramentos nas questões sociais agrícolas, no sentido de entender em que medida o trabalho docente dos professores egressos da LEC/UFBA está comprometido com a luta pela reforma agrária. Dos seis professores que tiveram trabalhos pedagógicos analisados, apenas o Professor 1 e a Professora 4 contemplam todos os critérios que foram estabelecidos na pesquisa desta tese. Tal constatação está bastante explícita em todos os instrumentos de pesquisa, com grande ênfase nas aulas que foram observadas e nas entrevistas.

Quadro 1 - Relação entre o trabalho docente dos egressos(as) da LEC e a defesa da reforma agrária.

\begin{tabular}{|c|c|c|c|c|c|c|}
\hline $\begin{array}{l}\text { Questão agrária/agrícola no } \\
\text { trabalho pedagógico }\end{array}$ & Pl & P2 & P3 & P4 & P5 & P6 \\
\hline $\begin{array}{l}\text { Trata a concentração } \text { da } \\
\text { propriedade privada da terra } \\
\text { como um problema social. }\end{array}$ & & & & & & \\
\hline $\begin{array}{l}\text { Relaciona as questões sociais } \\
\text { presentes no cotidiano escolar } \\
\text { com a questão da concentração } \\
\text { da propriedade da terra. }\end{array}$ & & & & & & \\
\hline $\begin{array}{l}\text { Identifica e faz constatações da } \\
\text { importância da agricultura } \\
\text { camponesa na garantia da } \\
\text { produção dos } \\
\text { consumidos no país. }\end{array}$ & & & & & & \\
\hline $\begin{array}{l}\text { Analisa cientificamente os } \\
\text { impactos do agronegócio no } \\
\text { meio ambiente, nas comunidades } \\
\text { tradicionais e na produção de } \\
\text { alimentos. }\end{array}$ & & & & & & \\
\hline $\begin{array}{l}\text { Reconhece as implicações da } \\
\text { política de produção agrícola do } \\
\text { agronegócio na soberania } \\
\text { alimentar. }\end{array}$ & & & & & & \\
\hline
\end{tabular}

Fonte: Elaborado pela autora (2015).

Na problematização da prática social inicial levantada em todas as aulas que foram analisadas, bem como nos documentos que serviram de subsídio para 
a pesquisa deste artigo, os dois professores mencionados tomam como referência a realidade concreta. Esta é marcada pela eclosão dos problemas agrários; por isso, eles são tensionados no movimento das aulas destes dois profissionais da educação, tanto no campo como na cidade. O tensionamento decorre do fato de eles mesmos serem peças-chave para o entendimento da realidade concreta: é aí que está o ápice da pedagogia históricocrítica, pois ela conduz o trabalho pedagógico em termos de orientação metodológica. Todavia, a qualidade da problematização e da instrumentalização que pode fazer o aluno compreender a realidade, para além dos fenômenos aparentes, parte, sobretudo, do nível de conhecimento que o professor tem para problematizar a prática social inicial e fazer a instrumentalização.

Tanto o Professor 1 como a Professora 4 têm a devida compreensão da questão agrária e suas implicações: eles analisam os processos socioespaciais a partir do discernimento de que os grandes problemas sociais brasileiros, do campo ou da cidade, são problemas advindos da questão agrária. Se o professor não tiver compreensão da realidade enquanto totalidade concreta, ele não saberá identificar o ponto onde se instalam os problemas socioespaciais presentes na prática social. Assim, não se trata só de problematizar a prática social inicial, mas, sobretudo, da relevância de ter conhecimento dela para fazer isto, trata-se do domínio do método.

O Professor desenvolve trabalho de alfabetizador de jovens e adultos no Programa Todos pela Alfabetização (TOPA), da Secretaria da Educação do Estado da Bahia. Nesse processo, ele criou condições para que os professores-cursistas entendessem o que está por trás do pseudodesenvolvimento que o capital internacional traz para a população do campo e dos municípios, conforme conclusão feita pelo mencionado professor sobre a realidade do Território de Identidade Agreste de Alagoinhas/Litoral Norte, ao considerar que "o desenvolvimento chegou pra aquele local segundo as ideias dos pactos socioeconômicos, mas não supera a pobreza. A pobreza continua lá! As pessoas morando em casas de taipa! Com pouca terra! Com saída do povo do campo pra cidade" (Professor 1).

O desenvolvimento é para quem? Quando há um tensionamento, ele conduz o aluno a identificar a concentração da propriedade privada da terra como um problema social e, do mesmo modo, relacionar as questões sociais presentes no cotidiano com a questão da concentração 
da propriedade da terra. Além disso, o Professor 1 também pontua os impactos da produção de eucalipto para a dinâmica da natureza, bem como para a soberania alimentar. Numa das aulas em que realizava a formação dos professores do TOPA, em Cardeal da Silva, ele perguntou: - $\mathrm{O}$ que plantavam aqui antes dos eucaliptos? As respostas foram: mandioca, milho, feijão, andu, batata, laranja, dentre outras. Com base nas respostas, ele fez a segunda pergunta: Alguém aqui come eucalipto? Essa pergunta gerou uma tensão sobre a questão que envolve o agronegócio e os impactos para a segurança alimentar. Assim, ele instrumentalizou a aula, mostrando as intenções do agronegócio que, além da exploração da mão de obra e da retirada da população do campo, muitas vezes entra na comunidade disfarçado de "anjo bom", ou seja, fazendo paliativos, gerando uma falsa ideia de que se trata de melhoria de fato.

O Professor 1 compreende que a escola está alheia às questões socioespaciais concretas, pois compreende que a questão agrária está dentro da escola, embora não seja tratada e nem visualizada, conforme transcrição de fala:

Então estas coisas passam por dentro da escola e a escola não enxerga os conflitos agrários! A negação de direitos! Tudo isso passa por dentro da escola. O aluno aprende o "a", o "b", o "c", mas não aprende que está disputando um pedaço de terra para viver. E que talvez, por conta destas questões objetivas, nem fique na escola! E a escola nem fique naquele lugar! (Professor 1).

O Professor 1 traz dois pontos relevantes: o primeiro diz respeito à escola, que não identifica a materialidade da prática social no currículo e no ensino, e o segundo versa sobre a estratégia de fechamento das escolas do campo. No primeiro, ele aponta que a questão agrária precisa perpassar o currículo escolar na superação do ensino utilitarista para uma alfabetização escolar que seja acompanhada da alfabetização da prática socioespacial. O indivíduo precisa aprender ler o mundo concreto que é produzido por ele mesmo, entremeado de conflitos entre as classes socais. Sendo assim, a Educação do Campo propõe uma escola comprometida com o projeto histórico-social de enfrentamento ao projeto histórico do capital. Essa ideia leva ao entendimento de que, em cada momento histórico, é preciso o ser humano saber quem ele é, com quem e contra o que luta, a fim de ter clareza de propósito ao traçar as táticas e estratégias de enfrentamento.

No segundo ponto, o Professor 1 trouxe uma relevante contribuição para pensar a questão agrária quanto à política de fechamento de escolas do campo. Tais ações estão sendo tomadas pelas 
secretarias de educação por secretários que são gestores e que compreendem a escola como um empreendimento a ser gerido por princípios de mercado, a partir das orientações fundamentadas na lógica do capital neoliberal. Assim, o fechamento das escolas tem sido justificado para a população como estratégia de ajuste econômico, haja vista que se compreende que não é vantagem, do ponto de vista financeiro, manter escolas com poucos alunos. Contudo, é notório que o fechamento de uma escola no campo também é acompanhado pelo fechamento de uma porta para a permanência do camponês naquele lugar. Tal como a saída do camponês é o caminho para o fechamento da escola. Assim, o Estado sai e o capital entra para se apropriar das terras do camponês e ampliar o seu negócio. Além do mais, é o Estado que atua contra os direitos dos camponeses e acaba fortalecendo as bases da estrutura do capital.

A Professora 4, ao explicar a relevância da LEC/UFBA, o faz com base nas contradições da questão agrária, conforme exemplo: "quando eu falo de campo tenho que ter conhecimento de latifúndio, de migração campo-cidade, exploração, escravidão, terra, lutas sociais" (Professora 4). Isso nada mais é do que reconhecer e ter domínio do processo contraditório da prática socioespacial. Ela diz: "não posso ensinar os alunos escrever simplesmente o nome terra ..., mas explicar porque os movimentos sociais lutam pela terra! Por que eles não têm a terra! Mas minha visão ingênua desconhecia como se originou os latifúndios" (Professora 4). E completa:
o MST é titulado réu na sociedade capitalista. Porque a sociedade desconhece a gênese dos conflitos da terra, e porque no estado da Bahia muitas das grandes propriedades são terras devolutas, uma minoria concentra as terras produtivas, e essas pessoas, os grandes latifundiários, são os que elegemos e que fazem leis para manutenção desses latifúndios. Essas perguntas não tinham respostas antes da Licenciatura em Educação do Campo (Professora 4).

Frisa-se que a pergunta para a qual a professora forneceu a resposta acima indagava sobre a importância da LEC para a formação dela. Não era uma pergunta voltada para a questão agrária no trabalho pedagógico. Mesmo assim, sua resposta representou o protótipo do professor ideal de Educação do Campo almejado há mais de vinte anos pelos movimentos de lutas populares camponesas - ela traz, no movimento da prática social, a síntese do que foi proposto pelo PPP/LEC/UFBA.

A Professora 4 destaca a importância de compreender os processos socioespaciais no movimento 
contraditório, mas sem perder as historicidades que estão subjacentes. Assim, explicar as contradições socioespaciais e a luta de classes é também tratar da questão agrária. A mencionada professora ainda faz o movimento entre os conceitos e a realidade: ela adentra a psicologia histórico-cultural para explicar que terra, antes de ser um conceito, é algo concreto e que, quando a terra é entendida como conceito abstrato, a realidade concreta fica de fora. Nesse contexto, ela faz a crítica às concepções que não partem da realidade concreta e que, portanto, não descobrem o que está por trás dos fenômenos dessa realidade e colaboram para que ela seja superada.

Outra questão apontada pela Professora 4 trata da relevância do ensino escolar para explicar a sociedade capitalista, pois, como o ensino escolar que é oferecido à classe trabalhadora é concretizado de forma fragmentada e em pequenas doses, a totalidade concreta não é explicada pela escola. Por isso, a realidade concreta não é entendida pela classe que vive os efeitos das condições postas pelo capital, de forma que os indivíduos dessa classe julgam as ações que visam o enfrentamento do capital a partir da lógica do próprio capital. Esses indivíduos se apropriam do que é propagado pelos meios de comunicação e criam a chamada falsa consciência: compreendem a realidade a partir dos interesses da classe dominante.

Trata-se de uma sociedade constituída por uma grande quantidade de pessoas sem terra, sem moradia, sem comida e sem educação e que não entendem os processos socioespaciais. Nessas circunstâncias, muitos indivíduos que vivem nas condições de pobreza assumem posicionamento político contrário às próprias condições que são por eles vividas. Isso se dá porque o referencial que é usado para formar a opinião que subsidia a decisão tomada não parte da sua prática social concreta. Desse modo, a Professora 4 adentrou o campo da ideologia e identificou a Educação do Campo enquanto espaço para a "desalienação" da classe trabalhadora. Com base nesse pensamento, a Professora 4 faz uma crítica à democracia representativa: a população, que não teve oportunidade de desenvolver a própria consciência, elege representantes para as instâncias do poder legislativo que legislam contra a classe que o elegeu.

A Professora 4, no decorrer do trabalho pedagógico, tensiona a questão agrária relacionando-a com as questões socioespaciais, identifica a importância da agricultura camponesa, destaca a importância da produção camponesa para a alimentação da população, destaca a 
questão do uso indiscriminado de agrotóxicos e alerta para os impactos do agronegócio nas comunidades tradicionais e na produção de alimentos. Como ela faz isso? Transitando a partir da análise de conjuntura e através de elementos da prática socioespacial, problematizando e instrumentalizando o real concreto.

No trabalho das demais professoras, as questões relacionadas à disputa por terra não são pontuadas. Mesmo que essas questões apareçam no processo de análise e problematização dos processos sociais, elas não são tratadas como questões agrárias, pois são tratadas na categoria genérica de questões sociais. Quanto ao trabalho das Professoras 2 e 6, apesar de terem claro a compreensão de projeto histórico, pode-se aferir que elas compreendem as contradições socioespaciais como contradições do capital, o que de fato é uma leitura acertada. Contudo, a questão agrária não está presente no trabalho docente: elas tratam de luta de classes, da relação capital/terra/trabalho, mas não tratam dos critérios supramencionados, ou seja, não dominam o método de análise teóricometodológico.

No que se refere à Professora 2, por trabalhar com cursos do PRONATEC, ela tensiona, em alguns momentos, os impactos do agronegócio no meio ambiente e na produção de alimentos, mas a posição está muito ligada às práticas que são desenvolvidas por dentro do curso. No caso das Professoras 3 e 5, por não identificarem as questões sociais na conjuntura da prática socioespacial, a questão agrária não é visualizada no trabalho pedagógico. Muitas vezes observou-se os fenômenos da questão agrária, mas eles não eram tratados como questão agrária. A Professora 2 pontua a violência como o principal limite para o trabalho na comunidade, mas ela não a associa, em nenhum momento, com a questão agrária local. A fração mínima para a divisão da propriedade da terra no município de São Felipe (BA), local onde a professora reside e trabalha, é de 3 hectares: contudo, $67,73 \%$ das propriedades têm área inferior a essa dimensão. Por outro lado, duas propriedades rurais do município têm dimensão superior a 500 hectares. Tais fatores interferem no índice de Gini local $(0,749)$, o que implica outros problemas socioespaciais.

Se a investigação saísse do trabalho docente e fosse analisada a partir da opinião dos professores, pode-se dizer que todos eles concordam que existe a questão agrária e que ela está no centro da questão estrutural do capitalismo. Mas o olhar desta pesquisa não foi voltado para a 
opinião dos professores, e sim para o interior do trabalho docente concreto, com o intuito de compreender como a questão agrária está sendo inserida no trabalho pedagógico. Considera-se que é este o propósito da Educação do Campo enquanto concepção de educação e tática de formação de professores para, a partir do trabalho docente, sua devida inserção na prática socioespacial.

As Professoras 3 e 5 encontram-se com domínio da dimensão da consciência em si: elas não têm consciência ingênua, tampouco falsa consciência, pois superam a percepção imediata e parcial da realidade, sabem que há luta de classes e sabem como o capital age e consegue identificar sua ação no movimento da prática social. As Professoras 2 e 6, por sua vez, têm consciência de classe, a de classe trabalhadora, mas a militância, aqui, se dá no campo pedagógico, no espaço escolar, na ocupação de programas que adentram a escola, que chegam fundamentados na pedagogia do capital e que elas ressignificam com base na pedagogia histórico-crítica e na teoria do conhecimento do materialismo históricodialético. Elas dão outro direcionamento no sentido tático de atender à classe trabalhadora a partir do Pacto Nacional pela Alfabetização na Idade Certa
(PNAIC), do PRONATEC e da Escola da Terra, dentre outros.

O Professor 1 e a Professora 4 têm consciência de classe nos atos: agem, cotidianamente, como intelectuais orgânicos no enfrentamento à questão agrária a partir de ideologia revolucionária, definindo metas e adentrando os campos conflituosos que mexem com a lógica do capital e com o direcionamento da política pública. O enfrentamento à questão agrária foi incorporado à prática social, o que indica que são ações que não exigem esforço, pois a realidade concreta se tornou realidade pensada e, portanto, praticada.

\section{Considerações finais}

Diante dos fatos supramencionados, compreende-se que nem todos os professores egressos da LEC/UFBA se apropriaram dos instrumentos necessários à implementação do projeto de escolarização da classe trabalhadora. Tratase de um ponto que exige outro estudo, no sentido de esclarecer o porquê dessa falta, cabendo aí um estudo do processo formativo. Contudo, é salutar destacar que a maioria desses/as professores/as se matriculou no curso com o intuito de ter acesso ao diploma de Ensino Superior, mas não foi só isso: o próprio processo formativo foi instalado em meio às diretrizes objetivas presentes nas condições 
concretas da instituição. Assim, muitos professores e coordenadores de área não participaram da construção do curso e se tornaram professores sem as condições teóricas e os fundamentos necessários para dar conta do curso do ponto de vista teórico e metodológico: aí se instalou uma disputa, um território, mesmo não tendo sido por conflito direto, mas por conflitualidades decorrentes do choque de concepções teóricas. É possível formar indivíduos para se tornarem sujeitos das lutas de classes dentro de concepções que sequer aceitam a existência da luta de classes?

No que se refere à efetivação do projeto de escolarização da classe camponesa, sabe-se que ele está adentrando os espaços da escola burguesa, sendo que esta tradicionalmente foi - e ainda é - um lugar conservador. Aí se instalam novos territórios, permeados de disputas de projetos de sociedade que divergem entre si. Todavia, foi possível constatar que os professores que se apropriaram dos fundamentos teóricometodológicos do materialismo históricodialético possuem seus respectivos trabalhos pedagógicos estrategicamente voltados para um projeto histórico que está associado à concepção de homem e de sociedade que se almeja ter. Para tanto, define-se, no plano tático, a concepção de teoria pedagógica que pode contribuir para explicar, no processo pedagógico, a realidade concreta. Isso implica descobrir o que está coberto nas expressões fenomênicas e entender o que está por dentro dos fenômenos, destruindo o mundo da pseudoconcreticidade. Esse é um movimento que está muito evidente nas ações de dois dos professores.

Entende-se que o objetivo da escola é produzir de forma intencional condições que permitam aos indivíduos singulares entenderem os processos socioespaciais e, automaticamente, também se entenderem: entender o espaço e as condições contraditórias em que é produzido. Se os indivíduos entendem a produção do espaço, passam a se entender também, haja vista que sociedade e espaço são inseparáveis - produções sociais que acontecem em concomitância. A compreensão de tal realidade depende da apropriação dos elementos teóricos orientados por um método que permita fazer semelhante leitura, pois não são apropriações do senso comum. Esse método é estabelecido no processo de apropriação do conhecimento que foi produzido historicamente pela humanidade a partir de intervenções pedagógicas.

Acredita-se que os alunos do Professor 1 e da Professora 4 têm mais probabilidade de alcançar a consciência de 
classe em si e para si e poderão, dessa forma, ter práticas sociais conscientes na defesa de um projeto de sociedade. No que se refere à Educação do Campo, é relevante saber que a consciência de classe pode tensionar o que fica obscuro em muitas das ações da classe trabalhadora no enfrentamento à questão agrária e ao posicionamento político na luta pela reforma agrária. Trata-se, afinal de contas, do principal pilar do capital: a concentração da natureza na condição de bem nada mais é que o controle da terra enquanto propriedade privada.

Implementar o projeto de escolarização da classe trabalhadora é fazer Geografia, é tensionar a estrutura do espaço geográfico dominado pelos interesses capitalistas. Isso remete ao pensamento Lefebvre (2000), pois as relações espaciais de produção não são dissociadas das relações sociais de produção, mas sim dialeticamente inseparáveis num processo denominado pelo autor de materialismo históricogeográfico. A lógica orientadora da prática social produz, ao mesmo tempo, relações sociais e seu espaço: se a Educação do Campo visa mexer com o modo como a sociedade se reproduz, ela automaticamente está comprometida com outra forma de espaço.
Para Lefebvre (2000), o espaço (social) é um produto (social), ele é um meio de produção e de controle que escapa parcialmente aos que dele se servem: o espaço, antes de ser um conceito, é uma realidade concreta que é produzida por um ser histórico concreto. Assim, para que a classe trabalhadora efetive o seu projeto histórico, ela precisa se apropriar da lógica que produz o espaço no qual a sociedade geradora toma forma se apresentando e representando, mas isso não se realiza em um dia. Trata-se de um processo que deve ser acompanhado pelo tensionamento da forma que garante a reprodução do capital: a concentração da propriedade da terra.

Com base nas observações desta investigação, reafirma-se o conceito de Taffarel (2013) de que Educação do Campo é luta da classe trabalhadora organizada, dos movimentos sociais que reivindicam e conquistam, gradativamente, escolarização com ensino de qualidade para que se desenvolva, em cada ser humano singular, o que foi fruto do desenvolvimento da humanidade. Por isso, essa perspectiva de educação da classe trabalhadora tem a necessidade de ser realizada a partir de uma consistente base teórica que permita formar o sujeito de classe na consciência da classe em si e para si, com formação política para contribuir com a organização revolucionária dos 
trabalhadores. Desse modo, a Educação do Campo tem sido minada pelo projeto do capital que a esvazia de conteúdo político e a retira da luta de classes, o que implica retirar o projeto histórico da classe trabalhadora. Portanto, Educação do Campo no Brasil é um território em conflito tanto quanto a sua tática é a luta pela reforma agrária.

\section{Referências}

Caldart, R. S. (2010). Educação do campo: notas para uma análise de percurso. Trab. Educ. $\quad$ Saúde, 7(1), 35-64. https://doi.org/10.1590/S198177462009000100003.

Engels, F. (2012). A origem da família, da propriedade privada e do Estado. São Paulo: Lafonte.

Freitas, L. C. (1987). Projeto histórico, ciência pedagógica e didática. Educ. $e$ Soci., (27), 122-140.

Freitas, L. C. (1995). Crítica da organização do trabalho pedagógico e da didática. São Paulo: Papirus.

Frigotto, G. (2010). A educação e a crise do capitalismo Real. São Paulo: Cortez.

Geografar. (2017). Estrutura fundiária. Recuperado de: https://geografar.ufba.br/estruturafundiaria

Germani, G. I. (2006). Condições históricas e sociais que regulam o acesso à terra no espaço agrário brasileiro. GeoTextos, 2(2), 2006, 115-147. https://doi.org/10.9771/19845537geo.v2i2.3040
IBGE - Instituto Brasileiro de Geografia e Estatística. (2006). Censo Agropecuário, 2006 - IBGE.

Lefebvre, H. (1991). The production of space. Cambridge, Mas: Blackvell Publishers.

Lefebvre, H. (2000). A produção do espaço. Recuperado de: http://www.mom.arq.ufmg.br/mom/02_arq interface/1a_aula/A_producao_do_espaco .pdf.

Martins, J. S. (1994). O poder do atraso. São Paulo: Hucitec.

Martins, J. S. (1981). Os camponeses e a política no Brasil: as lutas sociais no campo e seu lugar no processo político. Petrópolis: Vozes.

Marx, K. (1988). O capital: crítica da economia política. São Paulo: Nova Cultural.

Marx, K. (2004). Manuscritos econômicofilosóficos. São Paulo: Boitempo.

Marx, K., \& Engels, F. (2009). A ideologia alemã. São Paulo: Expressão Popular.

Moreira, R. (2012). Geografia e práxis: a presença do espaço na teoria e na prática geográficas. São Paulo: Contexto.

Ramos, L. R. S. (2013). A pesquisa didática na experiência da Licenciatura em Educação do Campo da UFBA: contribuição à formação científica dos professores (Dissertação de Mestrado). Universidade Federal da Bahia, Salvador.

Saviani, D. (2005). Pedagogia históricocrítica. Campinas: Autores Associados.

Smith, N. (1988). Desenvolvimento desigual: natureza, capital e a produção de espaço. Trad.: Eduardo de Almeida Navarro. Rio de Janeiro: Bertrand Brasil. 
Taffarel, C. N. Z. (2013). Convite de Formatura da Licenciatura em Educação do Campo. Salvador: Universidade Federal da Bahia.

Taffarel, C. N. Z. et al. (2011). Desafios da Educação do Campo na UFBA: proposições superadores - o Sistema de Complexos. In Molina, M. C. (Org.). Licenciaturas em Educação do Campo: registros e reflexões a partir da experiência-piloto (UFMG; UnB; UFBA e UFS) (s./p.). São Paulo: Autêntica.

Thomaz Júnior, A. (2009). Dinâmica Geográfica do Trabalho no Século XXI: (Limites Explicativos, Autocrítica e Desafios Teóricos). Presidente Prudente: Unesp,

(volume

1). http://www.athena.biblioteca.unesp.br/e xlibris/bd/livredocencia/2009/thomazjunior _a_ld_prud.pdf. Acesso em 26/07/2014.

UFBA. (2008). Projeto Político do Curso de Licenciatura em Educação do Campo. Universidade Federal da Bahia. Salvador.

\section{Informações do Artigo / Article Information}

Recebido em : 29/08/2021

Aprovado em: 12/10/2021

Publicado em: 13/11/2021

Received on August 29th, 2021

Accepted on October 12th, 2021

Published on November, 13th, 2021

Contribuições no Artigo: As autoras foram as responsáveis por todas as etapas e resultados da pesquisa, a saber: elaboração, análise e interpretação dos dados; escrita e revisão do conteúdo do manuscrito e; aprovação da versão final publicada.

Author Contributions: The author were responsible for the designing, delineating, analyzing and interpreting the data, production of the manuscript, critical revision of the content and approval of the final version published.

Conflitos de Interesse: As autoras declararam não haver nenhum conflito de interesse referente a este artigo.

Conflict of Interest: None reported.
Artigo avaliado por pares.

\section{Article Peer Review}

Double review

\section{Agência de Fomento}

Não tem.

Funding

No funding.

Como citar este artigo / How to cite this article

APA

Santos, J. B. (2021). A questão agrária na prática pedagógica dos/as professores/as egressos/as da LEC/UFBA: o desafio de efetivar 0 projeto de escolarização da classe trabalhadora. Rev. Bras. Educ. Camp., 6, e12940. http://dx.doi.org/10.20873/uft.rbec.e12940

ABNT

SANTOS, J. B. A questão agrária na prática pedagógica dos/as professores/as egressos/as da LEC/UFBA: o desafio de efetivar o projeto de escolarização da classe trabalhadora. Rev. Bras. Educ. Camp., Tocantinópolis, v. 6 , e12940, 2021. http://dx.doi.org/10.20873/uft.rbec.e12940 